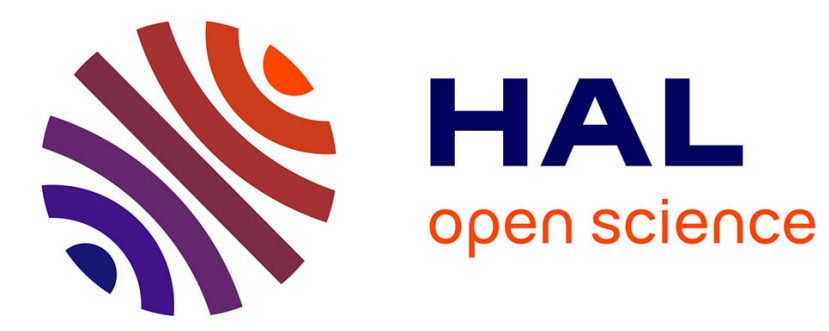

\title{
Collectif Pièces et mains d'oeuvre, Techno. Le son de la technopole
}

\author{
Arthur Devriendt
}

\section{To cite this version:}

Arthur Devriendt. Collectif Pièces et mains d'oeuvre, Techno. Le son de la technopole. Lectures, 2011, 1 p. halshs-00663086

\section{HAL Id: halshs-00663086 \\ https://shs.hal.science/halshs-00663086}

Submitted on 26 Jan 2012

HAL is a multi-disciplinary open access archive for the deposit and dissemination of scientific research documents, whether they are published or not. The documents may come from teaching and research institutions in France or abroad, or from public or private research centers.
L'archive ouverte pluridisciplinaire HAL, est destinée au dépôt et à la diffusion de documents scientifiques de niveau recherche, publiés ou non, émanant des établissements d'enseignement et de recherche français ou étrangers, des laboratoires publics ou privés. 


\section{«Collectif Pièces et mains d'oeuvre, Techno. Le son de la technopole »}

\section{Arthur Devriendt}

Référence : Arthur Devriendt, «Collectif Pièces et mains d'oeuvre, Techno. Le son de la technopole », Lectures [En ligne], Les comptes rendus, 2011, mis en ligne le 14 avril 2011. URL : http://lectures.revues.org/5213

Dans un livre au format resserré (94 pages), les membres du collectif grenoblois « Pièces et main d'œuvre» poursuivent leur critique radicale de la «technification» et du «mondemachine », cette fois-ci non plus en s'attaquant à une «technologie» précise (à l'instar des RFID, des nanotechnologies ou de la téléphonie mobile traités dans des ouvrages précédents) mais par le biais de la musique électronique (qualifiée abusivement dans son ensemble par le terme « techno »).

Selon les auteurs, cette musique s'impose comme la «bande-son de l'air du temps » : la thèse centrale de l'ouvrage est en effet que celle-ci accompagne et témoigne de «l'émergence du capitalisme high-tech, partageant sa soumission à la tyrannie technologique, son projet de monde hors-sol et sa fabrique de l'homme-machine postmoderne ». Pour preuve, le deejay masqué par ses «machines », les foules massées devant des murs d'enceintes glorifiées et s'agitant de manière mécanique... à l'instar de véritables « robots ».

Si un tel exercice de critique est toujours salutaire à l'heure des discours utopistes sur les technologies de l'information et de la communication, la société de l'information ou l'économie de la connaissance, en revanche, l'argumentation mobilisée est très faible, oscillant entre jugements de valeurs, raccourcis et méconnaissance des travaux universitaires.

Tout d'abord, bien que les auteurs du collectif déclarent en préambule ne pas se placer sur le plan de la critique musicale, force est de constater que leur ouvrage est traversé de jugements de valeurs : la «techno » est ainsi considérée tout à la fois comme «bruit», « assommoir » et dépourvue de «lexique » et de «grammaire». Les auditeurs sont quant à eux décrits comme «autistes », «masochistes » et dénués de toute conscience politique. Affirmations très peu étayées, consistant en des généralisations basées pour l'essentiel sur le ressenti propre aux auteurs, et non suite à un travail d'enquête auprès des populations ainsi visées...

A cela s'ajoute un grand nombre de raccourcis et propos caricaturaux. Il en est notamment ainsi quand les auteurs dénoncent l'établissement de fêtes « techno » dans des lieux jusque là « de pleine nature »... et prennent pour exemple la Bastille de Grenoble, en feignant d'ignorer les actions séculaires d'aménagement par l'Homme que ce site a connu. Dans un autre registre, les auteurs affirment qu'il n'existe que «peu [voire] pas de musiques électroniques dans les pays du tiers-monde ». Mais, entre autres genres musicaux, quid du Kuduro né dans les années 1990 en Angola, qui a envahi progressivement l'ensemble du continent africain et qui se diffuse aujourd'hui largement au-delà de ses frontières ?

Enfin, lors de la lecture, on ne peut s'empêcher de penser à la multitude de travaux universitaires semblant invalider les thèses du collectif «Pièces et main d'œuvre », qu'il s'agisse de l'uniformisation des modes de vie au temps de la mondialisation ou de la passivité des individus dans un schéma émetteur - récepteur bien trop réducteur. Les auteurs ne se livrent cependant pas à une critique de ces travaux mais se contentent de rejeter en bloc les « sociologues de supermarché », les «para-universitaires » et leurs «flots d'inepties ». Seuls Gilles Deleuze et Felix Guattari font l'objet d'une attention particulière... mais d'une lecture très parcellaire : le collectif voit en effet dans le concept de « déterritorialisation » forgé par ces auteurs (surnommés «Deleuze \& Guattari Inc.») l'apologie de la globalisation et de l'émergence d'un monde sans lieux que la «techno» accompagnerait. C'est là oublier son 
corollaire, la «reterritorialisation », et la place centrale accordée à l'espace par les deux philosophes dans leur travail.

Si aujourd'hui plus que jamais, le «système technicien» doit être observé et analysé, la critique de la technique a besoin de tout autre chose que du « harcèlement textuel ${ }^{1} » \ldots$

\footnotetext{
${ }^{1}$ Site internet du collectif « Pièces et main d'œuvre » : http://www.piecesetmaindoeuvre.com/spip.php?page=plan
} 